\title{
NEW LIGHT ON PARASOREX DEPERETI (ERINACEOMORPHA: ERINACEIDAE: GALERICINI) FROM THE LATE MESSINIAN (MN 13) OF THE MONTICINO QUARRY (BRISIGHELLA, FAENZA, ITALY)
}

\author{
FEDERICO MASINI ${ }^{1, *}$, ANDREA SAVORELLI ${ }^{2}$, ANTONIO BORRANI ${ }^{1}$, PAUL P. A. MAZZA ${ }^{2}$, FLAVIANO FANFANI ${ }^{2}$
}

${ }^{1}$ Department of Earth and Marine Sciences (DISTEM), Università di Palermo, Via Archirafi 22, 90123 Palermo, Italy;

e-mail: federico.masini@unipa.it, antonio.borrani@unipa.it.

2 Dipartimento di Scienze della Terra, Università di Firenze, via G. La Pira 4, 50121 Firenze, Italy;

e-mail: andrea_savorelli@yahoo.it, paul.mazza@unifi.it.

* corresponding author

Masini, F., Savorelli, A., Borrani, A., Mazza, P. P. A., Fanfani, F. (2019): New light on Parasorex depereti (Erinaceomorpha: Erinaceidae: Galericini) from the Late Messinian (MN 13) of the Monticino Quarry (Brisighella, Faenza, Italy). - Fossil Imprint, 75(3-4): 438-453, Praha. ISSN 2533-4050 (print), ISSN 2533-4069 (on-line).

\begin{abstract}
A large-sized species of Parasorex is common in the MN 13 mammal assemblages from the uppermost Messinian sandy-marly fissure fillings within the Gessoso Solfifera Formation at Brisighella (Northern Apennine). This erinaceid has been classified as Galerix sp. in the first papers on the Brisighella fauna. Later, it was described in detail in an unpublished Ph.D. dissertation by Fanfani (1999), who referred it to Galerix depereti. Van den Hoek Ostende (2001) included G. depereti in the genus Parasorex, Parasorex depereti has been described by Crochet (1986) on scarce material from a few Early Pliocene (MN 14-15) localities of southern France and Spain. Parasorex cf. depereti has been reported from the Early Pliocene fauna of Capo Mannu (Mandriola, Sardinia; Furió and Angelone 2010). The species seems actually distributed in south-western Europe, where it represents the youngest occurrence of the genus Parasorex. The very abundant sample of $P$. depereti from fissure filling BRS 25 enables a more accurate and comprehensive description of the species. It also permits inspection of the mesial elements of the dentition, which were lacking in the material examined by Crochet (1986). The systematic position of the species has been revisited and compared with those of other Galericini of the Parasorex group.
\end{abstract}

Key words: Parasorex, Messinian, taxonomy, biometry, emended diagnosis

Received: March 30, 2019 | Accepted: October 7, 2019 | Issued: December 30, 2019

\section{Introduction}

The Monticino Quarry at Brisighella (Text-fig. 1) is one of the most remarkable Late Messinian localities in Italy, particularly for its terrestrial fauna. Fossil remains of vertebrates were found in August 1985 by Antonio "Tonino" Benericetti, Marco Sami, Giampaolo Costa (Civic Museum of Natural History of Faenza), Stefano Marabini and Prof. Gian Battista Vai (University of Bologna) in cavity fillings that intersect the Messinian evaporites (Costa et al. 1986). These researchers also involved the vertebrate palaeontology group of the University of Florence for the study of vertebrates.

The network of cavities, which are prevalently of karstic origin, developed in the tilted Gessoso Solfifera evaporite

Text-fig. 1. Location map of the Monticino quarry near Brisighella, Emilia-Romagna region, north-eastern Italy.

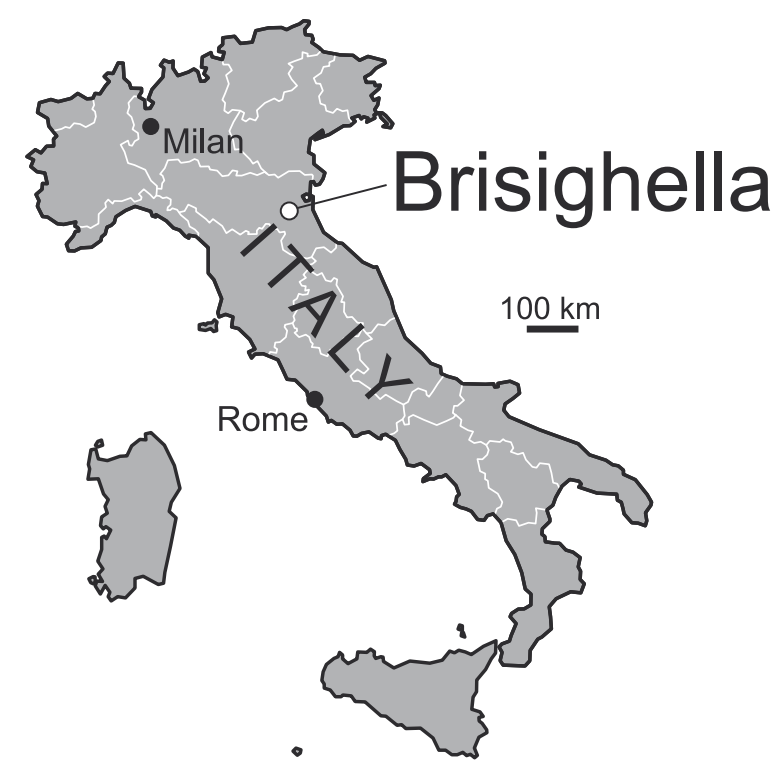


bedrock. The cavities are sealed locally by uppermost Messinian brackish sediments of the Colombacci Formation (Lago Mare). A thick cover of rhythmic laminated marine clays (Argille Azzurre FM), the base of which is earliest Pliocene in age (Sphaeroidinellopsis zone), conformably overlies the Colombacci FM. The geology constrains the age of the fissure fillings to a time period younger than the intra-Messinian tectonic phase that was responsible for the tilting of the Gessoso Solfifera FM. This event was slightly older or possibly contemporaneous with the Colombacci FM (Marabini and Vai 1989).

The fissure filling yielded remains of both large and small vertebrates, but the latter greatly outnumber the former. Costa et al. (1986) first reported the occurrence of a moonrat, which they identified as "Echinosoricinae cf. Galerix". In papers published during the late ' 80 s - early ' 90 s of the last century, the moonrat was called Galerix sp., or Galerix sp. aff. depereti (De Giuli 1989, Masini 1989, Masini and Thomas 1989, Torre 1989, Masini and Rook 1993). Fanfani (1999), in his unpublished dissertation, provided the first detailed description of this taxon, which he attributed to Galerix depereti. Van den Hoek Ostende (2001) included G. depereti in the genus Parasorex, whereas Ziegler (2005) accommodated it in Schizogalerix. Van den Hoek Ostende's (2001) opinion is supported by the results of Borrani et al. (2017) phylogenetic analysis; for this reason, Van den Hoek Ostende's (2001) attribution is shared by the writers.

After Fanfani's (1999), this is the first updated description of Parasorex depereti from fissure BRS 25, which is the richest record of the species. Parasorex depereti from BRS 25 considerably enhances our knowledge of the species and of its morphological variability. Incisors, canines and monocuspidate premolars are here described for the first time; they complete the original description of the species made by Crochet (1986).

\section{Material and methods}

The sample studied in this paper includes: a partial left upper maxillary preserving P4-M2 toothrow, 14 fragmental mandibles, 5 of which still preserve some teeth. The majority of the material studied is represented by isolated teeth: lower incisors (total 70), c (20), p1 (9), p2 (15), p3 (48), p4 (53), $\mathrm{m} 1$ (31), m2 (47), m3 (31); upper incisors (total 80), C (15), P1 (20), P2 (20), P3 (30), P4 (17), M1 (40), M2 (69), M3 (33). The material is stored at the Museo Civico di Scienze Naturali Malmerendi of Faenza (MSF, Ravenna, NorthEastern Italy) with catalog numbers from MSF 2401 to MSF 3064. Basic statistical parameters are presented in Table 1; all measurements are expressed in millimeters. Measurements follow Prieto et al. (2010); for details see the explanations in Table 1. Dental morphological terms are based on Borrani et al. (2017). The material has been measured using a Leitz Wetzlar Elvar microscope equipped with a Wild Heerbrugg MMS 235 measuring system, and photographed with a Leica DC150 system mounted on a Wild Heerbrugg Type 308700 microscope.

Dental sizes of specimens from different samples and localities were compared using a simplified, non-logarithmic version of the "Simpson Log-Ratio Diagram" method (Simpson 1941, Masini and Fanfani 2013). The standard for these comparisons was Parasorex socialis from la Grive Saint Alban, because this is the type species of the genus.

\section{Abbreviations}

DST Earth Science Department of the University of Florence, Italy

MSF Museo Civico di Scienze Naturali Malmerendi of Faenza, Italy

MTH Université de Montpellier II, Laboratoire de Paléontologie, France

Table 1. Basic statistic parameters of upper and lower cheek teeth, number of measured specimens $\left(\mathrm{N}^{\circ}\right)$, mean, minimum $\left(\mathrm{Min}^{\circ}\right)$, maximum (Max.) and standard deviation (St.dev.). For lower premolars and molars: L: total length of the crown in p3-m3 (L in Prieto et al. 2010); Wp3: maximum width of $\mathrm{p} 3$ (W2 in Prieto et al. 2010); Wp4: maximum width of p4 (W2 in Prieto et al. 2010); WTAL1: maximum width of the talonid of $\mathrm{m} 1$ (W2 in Prieto et al. 2010); WTAL2: maximum width of the talonid of $\mathrm{m} 2$ (W2 in Prieto et al. 2010); WTR3: maximum width of the trigonid of $\mathrm{m} 3$ (W1 in Prieto et al. 2010). For upper premolars and molars: L: length at the labial border of the crown in P3-M3 (L1 in Prieto et al. 2010); WP3: width of the third upper premolar taken orthogonal to the length; WP4: width of the fourth upper premolar taken orthogonal to the length, from the lingual profile of the crown to the innermost point of the lingual profile; WPP4: width of the fourth upper premolar taking the base of the pillar of the paracone as labial reference point (W1 in Prieto et al. 2010); WPM1: width of the M1 taken at the posterior profile of the crown (W2 in Prieto et al. 2010); WAM2: width of the M2 taken at the mesial profile of the crown (W1 in Prieto et al. 2010); WM3: maximum breadth of the crown (W in Prieto et al. 2010). All measurements are in millimetres.

\begin{tabular}{|c|c|c|c|c|c|c|c|c|c|c|c|c|c|}
\hline Tooth & $\mathbf{N}^{\circ}$ & Measure & Mean & Min. & Max. & St.dev. & Tooth & $\mathbf{N}^{\circ}$ & Measure & Mean & Min. & Max. & St.dev. \\
\hline \multirow[t]{2}{*}{ p3 } & 48 & Lp3 & 2.08 & 1.80 & 2.24 & 0.10 & P3 & 20 & LBP3 & 2.22 & 1.98 & 2.45 & 0.11 \\
\hline & & Wp3 & 1.09 & 0.98 & 1.22 & 0.07 & & & WP3 & 1.94 & 1.68 & 2.15 & 0.13 \\
\hline \multirow[t]{2}{*}{ p4 } & 53 & Lp4 & 2.41 & 2.18 & 2.65 & 0.10 & P4 & 17 & LBP4 & 2.86 & 2.65 & 3.03 & 0.11 \\
\hline & & Wp4 & 1.48 & 1.32 & 1.70 & 0.07 & & & WPP4 & 2.75 & 2.60 & 2.95 & 0.08 \\
\hline m1 & 31 & Lm1 & 3.27 & 2.97 & 3.54 & 0.15 & M1 & 40 & LBM1 & 2.93 & 2.71 & 3.12 & 0.10 \\
\hline \multirow[t]{2}{*}{$\mathbf{m} 2$} & 47 & Lm2 & 2.78 & 2.48 & 2.97 & 0.12 & M2 & 69 & LBM2 & 2.50 & 2.31 & 2.73 & 0.08 \\
\hline & & WTAL2 & 1.99 & 1.77 & 2.18 & 0.10 & & & WAM2 & 3.27 & 3.05 & 3.55 & 0.11 \\
\hline \multirow[t]{2}{*}{ m3 } & 31 & Lm3 & 2.49 & 2.32 & 2.77 & 0.09 & M3 & 24 & LBM3 & 1.64 & 1.48 & 1.82 & 0.10 \\
\hline & & WTR3 & 1.41 & 1.32 & 1.20 & 0.06 & & & WM3 & 2.32 & 2.16 & 2.54 & 0.10 \\
\hline
\end{tabular}




\section{Systematic palaeontology}

Parasorex depereti has been described by Crochet (1986) on rather scarce material from some Early Pliocene (MN 14-15) localities of southern France and Spain. The species was actually distributed in south-western Europe, where it represents the youngest occurrence of genus Parasorex.

The diagnosis provided by Crochet (1986) has been revised in the light of Monticino quarry's fossil record. The latter is far richer than that on which the species had originally been described.

Class Mammalia Linnaeus, 1758

Order Eulipotyphla Waddell, OKada et Hasegawa, 1999 Suborder Erinaceomorpha GrEgORY, 1910

Family Erinaceidae Fischer, 1814

Subfamily Galericinae PoMel, 1848 Tribe Galericini PoMel, 1848

Genus Parasorex von MEYER, 1865

Parasorex depereti (CROCHET, 1986)

Text-fig. 2, Pls 1-3

Synonymy for fissure BRS 25 material:

1986 Echinosoricinae cf. Galerix; Costa et al., pp. 221-235.

1988 Galerix sp. aff. depereti; De Giuli et al., pp. 65-67.

1989 Galerix sp. aff. depereti; De Giuli, p. 198.

1989 Galerix sp.; De Giuli, p. 199, tab. 1.

1989 Galerix sp.; Masini, p. 296, tab. 1.

1989 Galerix sp.; Masini and Thomas, p. 308, tab. 1.

1989 Galerix sp.; Torre, p. 326, tab. 2.

1993 Galerix sp. aff. depereti; Masini and Rook, p. 80, tab. 1.

1999 Galerix depereti; Fanfani, pp. 28-35, tabs I.4, IX.4.

2013 Parasorex depereti; Masini and Fanfani, pp. 101-102, tab. 2, fig. 9B.

H o l o t y p e. MTH 1, right M1.

Ty p e lo c a lity. Mt. Hélène, Pyrénées-Orientales, France.

O c currences. Italy: Brisighella, Borro Strolla (Abbazzi et al 2008), Sardinia (Capo Mannu D1 Mandriola) (Furió and Angelone 2010); France: Celleneuve, Vendargues, Terrats, Mt. Hélène, Nimes (Crochet 1986); Portugal: Esbarrondadoiro (Alvalade basin) (Antunes and Mein 1989).
Stratigraphic range. Late Miocene (MN 13) Early Pliocene (MN 15).

Studied material. Material included in this study originates from fissure BRS 25 (see Material and methods for details).

Repository. Civic Museum of Natural History "Malmerendi" of Faenza (for fissure BRS 25 material).

Original diagnosis. This is the largest species of the genus. Morphologically, it differs from G. exilis based on the same characters that discriminate the latter from G. socialis, i.e., the presence of a bi-cusped labial lobe on P3 and of a posterior crest on the metaconule of the upper molars extended to the postero-labial corner of the crown (Crochet 1986, translated from French).

Emended diagnosis. Large-sized Parasorex. P3-P4 with a large, distally-expanded lingual lobe; P3 with a significant proportion of single cusped lingual lobe; large, prominent hypocone on $\mathrm{P} 4$; small protoconule on upper molars; more squarish M1-M2s respect to most of the other Parasorex species, with centrocrista but without mesostyles; with hypocone and protocone separated by deep notch and with low prehypocrista; $\mathrm{p} 2$ smaller than $\mathrm{p} 3$ and frequently with anterior cusp, with roots that tend to fuse; $\mathrm{p} 4$ with a high metaconid inclined lingually and with high paraconid; lower molars with low and short distal cingulid, never connected with the postentocristid (labial arm of entoconid).

Description. Dental formula. I3/?3 C 1/1 P 4/4 M 3/3.

Detailed description of the teeth. Fossil anterior premolars, canines and incisors of Galericini are poorly known, with a few remarkable exceptions (e.g. Galerix exilis; Ziegler 1983). This could result in some uncertainty in the identification of some of these teeth if they are isolated.

The canines, and the first lower and upper incisors can be easily distinguished from the other unicuspid teeth. More difficult are the second and third upper and lower incisors. In the case of the examined material, it is still difficult to assess if whether the BRS hedgehog had three or two lower incisors. In the upper anterior tooth row, I2 is usually larger than I3, P1 has a simple, single-cusped crown and two fused roots, between which lies a shallow vertical groove that separates them. P2 is much larger, has a talon-shaped
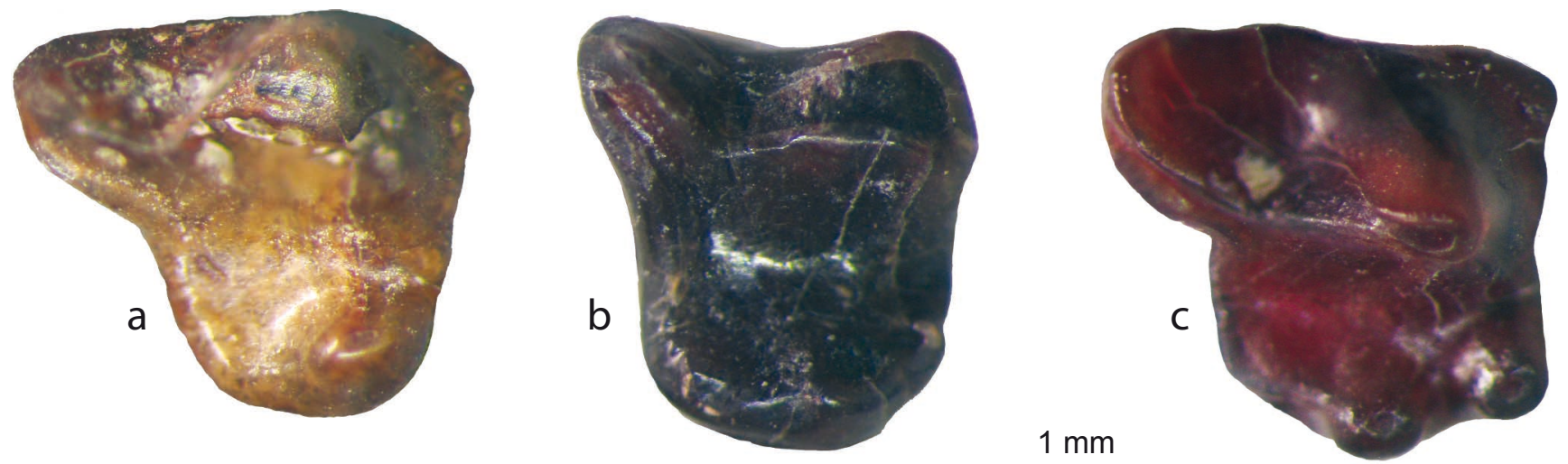

Text-fig. 2. P3, morphotypes of Parasorex depereti from BRS 25. a) P3 with only one lingual cusp, hypocone. b) P3 with fused protocone and hypocone, forming a ridge-like complex. c) P3 with well-developed protocone and hypocone. Scale bar $1 \mathrm{~mm}$. 
posterior border, rarely an anterior bulge close to base of the crown and two widely separated roots.

I1. The first incisor is the largest of the anterior tooth row (Pl. 1, Fig. 1, Pl. 2, Fig. 1). It is a robust "canine-like" tooth, probably vertically implanted. The root is massive, longer than the crown, bent with posterior concavity and moderately flattened mesio-distally. The crown is pointed and sub-triangular in cross-section, with a somewhat flattened internal side faced to the contralateral I1 and a convex external (lateral) side. The crown is uniformly very worn, especially on its rear side, often all the way to the base of the crown.

I2 and I3. Many unicuspid teeth, smaller than I1, with sub-conical crown and bent root can be referred to I2s and/or I3s (Pl. 1, Figs 2, 3, Pl. 2, Figs 2, 3). The crown is subconical, with convex antero-labial side and flattened posterolingual side; in the larger ones the posterior side has a weak posterior bulge at the base and is generally worn in a way to generate a sharp rear edge. The root is proportionally shorter than in I1 and slightly curved with posterior concavity and moderately flattened labio-lingually. The smallest of these incisors are very slender and have a short, subconical, slightly procumbent crown. The posterior bulging is always faint. These teeth appear constantly unworn or only moderately worn. With respect to the crown, the root is proportionally longer than in the larger incisors and sub-oval in cross-section. Because in several Galericini species the incisors become smaller from I1 to I3, the smallest incisors from BRS 25 can be interpreted as I3s and the medium-sized ones as I2s. However, in Parasorex ibericus, which has a shorter muzzle than other gymnures, I2 is the smallest of the three incisors (Mein and Martín-Suárez 1993: figs 1, 2).

C1. The upper canine is a two-rooted tooth, triangular in side view, somewhat similar to P2 (Pl. 1, Fig. 4, P1. 2, Figs $4,5)$. The crown consists of a single, high, pointed, slender cusp, compressed linguo-buccally, with a concave, sharp, rear side. It is higher than the second premolar and has a small basal bulge at the distal end of the crown. The roots are long, compressed labio-lingually, sub-triangular in cross-section, and strongly divergent antero-posteriorly. The anterior root is curved and the posterior one is slightly larger and straight.

P1. The single root of this tooth is often divided by a deep, vertical furrow (Pl. 1, Fig. 5, Pl. 2, Fig. 7). The crown consists of a single, slender, pointed cusp, whose tip bends

Table 2. Morphotypes of the cusps of the inner lobe of P3s of Parasorex depereti from BRS 25. N - number of specimens; $\%$ - percent frequency. Also the occurrence of feeble parastyle is reported.

\begin{tabular}{|lcc|}
\hline Morphotype & N & \% \\
\hline Protocone approximately as large as the hypocone & 15 & 50 \\
Protocone smaller than the hypocone & 7 & 23.33 \\
Hypocone is the only lingual cusp & 3 & 10 \\
Hypocone developed, rudimentary protocone & 3 & 10 \\
Presence of a cuspule distal to the hypocone & 1 & 3.33 \\
Crest-like hypocone & 1 & 3.33 \\
Occurrence of feeble parastyle & 6 & 20 \\
\hline Total number of examined specimens & 30 & - \\
\hline
\end{tabular}

slightly backwards. It is slightly procumbent, with a smooth weak anterior bulge and a low, variably-developed posterior one.

P2. This tooth resembles the upper canine (P1. 1, Fig. 6, Pl. 2, Figs 6, 8). It has a single, high cusp, somewhat mesially situated, which is extended posteriorly by a low talon with a distinct accessory cusp on the labial corner. The main cusp is lower, less pointed and less flattened labio-lingually than that of the canine and its posterior edge is smooth. The crown is sub-triangular in side view and sub-oval in occlusal view. It has two sub-equal roots, the anterior one somewhat arched with posterior concavity and the posterior one straighter and slightly larger.

P3. This tooth is a sort of miniature P4 (Pl. 1, Fig. 7, Pl. 2, Figs 9-12). Occlusally, the outline of the tooth ranges from squarish to trapezoidal: the labial border is weakly oblique to the sagittal axis of the tooth, the posterior profile is moderately to very emarginated, the labial side is occupied by the large, high paracone whose posterior ridge (postparacrista) extends into a low, but well-developed crest (metastylar crest), often forming a carnassial notch; the lingual side consists of a low and wide lobe on which the protocone and hypocone are situated. The protocone is placed in the mesio-lingual corner of the tooth, and sometimes protrudes mesially. The part of the lingual lobe extending behind the hypocone forms a rather wide and flattened basin delimited lingually and posteriorly by a cingulum that becomes thicker at the postero-labial corner of the crown. The relative size, position and shape of the two lingual cusps, protocone and hypocone, vary considerably (Text-fig. 2, Tab. 2). In general, they are located rather anteriorly on the lingual lobe, with the hypocone that protrudes more lingually than the protocone. Morphologically, the protocone and hypocone sometimes form a ridge-like structure, whereas in one case only the hypocone is ridge-shaped. Six specimens have only one lingual cusp, which can be interpreted as a hypocone migrated mesially. Such inference is supported by the observed mesial displacement of both proto- and hypocone in the teeth with bicuspid inner lobes, and more so, by three single-cusped $\mathrm{P} 3 \mathrm{~s}$, which have a rudimentary protocone placed mesially just against the base of the paracone. In seven other specimens the protocone is smaller than the hypocone and is situated more labially; in one case, the hypocone and protocone tend to merge; rare specimens (two) show an additional cusp behind the hypocone (Textfig. 2). The preprotocrista is absent; sometimes, a faint ridge-like parastyle occurs at the mesio-labial corner of the paracone. P3s have three roots; the lingual root is large and not subdivided, but shows a marked vertical furrow on its lingual side.

P4. The tooth is larger and less variable morphologically than P3 (P1. 1, Fig. 8, Pl. 2, Figs 13-16, 20). Behind the high, robust paracone is situated a sharp postparacrista, which connects with the metastylar crest forming a carnassial notch in between. The metastylar crest extends to the postero-labial corner of the tooth. The tooth has a less emarginated posterior profile than P3. The lingual lobe is wide labio-lingually and extends posteriorly; it is delimited by a strong, posterolingual cingulum, which reaches the postero-labial corner of the crown and usually merges with the base of the hypocone, enclosing a wide basin. The protocone is the higher of the 
two lingual cusps, but the hypocone is still well-developed; in a few cases, the two cusps may be of similar size. Both are situated somewhat anteriorly. Sometimes a posterior bulge forms a sort of third lingual cusp on the posterior cingulum, close to the hypocone.

A preprotocrista is always present; sometimes it is directly connected with the parastyle, which occupies the anterolabial corner of the tooth. The latter is a lingually extended ridge, which can reach the preprotocrista without merging with it. The roots are like those of P3 but the vertical furrow on the inner side of the lingual root is somewhat deeper.

M1. The first upper molar is the largest tooth of the upper row (Pl. 1, Fig. 9, Pl. 2, Figs 17-21). Occlusally, it has a sub-rectangular (trapezoidal) outline, with a protruding postero-labial corner. The labial border is gently concave, due to the labio-distal projection of the mesostylar ridge. A fairly continuous narrow labial cingulum is always present. The parastyle is well-developed and connected with the low anterior cingulum. The mesostyle (centrocrista sensu Lopatin 2006) is practically absent; it consists of a very low and thin crest connecting the posterior arm of the paracone with the anterior arm of the metacone, and cut by a deep notch. The metaconule is large and crescent-shaped, with a posterior arm extended to the postero-lingual corner of the crown (a taxonomically significant character for taxa with Parasorex-Schizogalerix affinities).

The metacone is higher than the protocone. The latter is connected labially, through the preprotocrista, with a small, narrow cusped paraconule with no posterior arm. The mesial arm of the protoconule usually merges with the lingual side of the paracone, or rarely, dips and extends anteriorly along the base of the paracone. In rare specimens a low, additional tubercle may occur lingually at the base of the protocone. The high, crest-like posterior arm of the protocone (postprotocrista) joins the anterior arm of the hypocone, but in $17 \%$ of the specimens, it branches also towards the metaconule and joins it (triple connection in Borrani et al. 2017). The valley between the metaconule and the posterior arm of the protocone is very shallow. The connection between the hypocone and the posterior arm of the protocone is always in the form of a low crest, which makes the tooth appear somewhat "primitive". The posthypocrista is rarely visible, however, in worn teeth, the postero-labial side of the hypocone forms a sort of crista that merges with a weak posterior cingulum, which is interrupted by the posterior arm of the metaconule. In the sample from BRS 25 a continuous labial cingulum occurs, which does not extend to the postero-lingual corner. M1 has three roots: the lingual root is largest and seems to result from the fusion of two roots of different size, aligned antero-posteriorly to one another.

M2. The tooth is smaller than M1, from which it differs in having: a sub-rectangular occlusal outline, with convex anterior edge, shorter and non-prominent postero-labial corner and shorter metastylar ridge (metacone posterior arm) and posterior arm of the metaconule (Pl. 1, Fig. 10, Pl. 2, Figs 20,22-25). The labial border is concave, with a narrow, variably-developed labial cingulum. A weak mesostylar crest rarely forms a bulge at the end of the anterior arm of the metacone. Unlike M1, in M2 the protocone is the highest cusp. Similarly to M1, in M2 the protocone has a high posterior arm directed towards the metaconule, and reaches it more frequently (26\%) than in M1. In some of these specimens the prehypocrista connecting the hypocone and the posterior arm of the protocone is very low and weak (P1. 2, Fig. 24). In the M2, a low anterior arm of the hypocone meets the posterior arm of the protocone at open angles; rarely the two arms form a continuous, arched ridge. Like in M1, but more frequently and more markedly than in the latter, the labial arm of the paraconule dips and extends anteriorly along the base of the paracone. The roots are morphologically like in M1.

M3. The tooth is triangular-shaped in occlusal view, but can be variably extended antero-posteriorly (Pl. 1, Fig. 11, P1. 2, Figs 26-28). It is much smaller than M2. The crown includes a conical paracone, higher than the metacone and slightly lower than the protocone. The crescent-shaped protocone, placed lingually to the paracone, is the largest cusp. The metaconule is absent. The anterior arm of the protocone runs towards the paracone, dipping and finally merging with its base; a small bulge-shaped paraconule may occur. A well-developed parastyle is always present; it extends lingually, fusing with the anterior cingulum. The labial and posterior cingulum are missing or extremely reduced. Protocone and metacone are always connected by a continuous crest. The mesostyle is absent and a straight, low crest connects the paracone with the metacone. The tooth has three roots, the lingual one being the largest.

i1. This is the largest lower incisor; it is stouter than i2 and $i 3$ and slightly larger, on average, than the canine (Pl. 1, Fig. 12, Pl. 3, Fig. 1). The crown is spatulate and oblique labially. It is convex ventro-laterally (labially) and concave dorsal-lingually. A marked cingulid is present close to the collar, on the dorso-labial side of the tooth. The root is long, somewhat flattened labio-lingually and bent with dorsal (occlusal) concavity. The root ends in a flattened hook tip in some specimens.

i2. The second lower incisor (Pl. 1, Fig. 13, Pl. 3, Fig. 2) is a spatulate, procumbent tooth, smaller than both i1 and canine; it resembles the canine in many respects, having a less flattened crown than i1. The mesial side is rounder and the disto-dorsal side more concave than i1; the tooth bears a small lateral bulge on its dorso-labial side. Anteriorly, at the dental collar, crown and root are arranged in a weak arched pattern with ventro-lingual concavity. The root may present a longitudinal and shallow furrow separating a ventral and a dorsal portion. The distal end of the root is often fashioned as a flat hook.

i3?. A few incisors differ from i2 by being smaller, more concave ventro-lingually and by having shorter root. These teeth are tentatively identified as i3 (Pl. 1, Fig. 14, Pl. 3, Fig. 3).

c1. The incisor-like canine differs from the first lower incisor by being slightly smaller and by having a relatively shorter, straight root. It is implanted obliquely on the mandible (Pl. 1, Fig. 15, Pl. 3, Fig. 4). The crown is short, aligned with the root, with which, observed occlusally, it is arranged in an arched pattern labially. The root is flattened latero-medially and often furrowed longitudinally, with a larger dorsal portion and a smaller ventral one. The crown is blade-like, with a sharp postero-dorsal edge and blunt and worn tip, and is somewhat procumbent on the second/third 
incisor. The labial side is convex and the lingual one slightly concave. Wear affects also the lingual side. A small bulge is present close to the collar on the rear side of the dorsal edge.

p1. p1 and $\mathrm{p} 2$ are simple-crowned teeth with one or two roots, usually fused; $\mathrm{p} 1$ is smaller than $\mathrm{p} 2$ and has a simpler crown (P1. 1, Fig. 16, Pl. 3, Fig. 5); morphologically, it is a simplified version of $\mathrm{p} 2$, with lower main cuspid and the accessory anterior labial cuspid fused to it in such a way as to form a procumbent anterior bulge in the crown. The posterior lingual cuspule is smaller than in $\mathrm{p} 2$. The tooth has one root; in some specimens a shallow vertical furrow may occur.

p2. Small tooth with a sub-elliptical occlusal profile (P1. 1, Fig. 17, Pl. 3, Figs 6-8). The crown is sub-triangular in side view, with slender main cuspid. A smoothed accessory cuspid is present antero-labially, placed at about half the height of the crown; the posterior side prolongs distally and bears a low basal accessory cuspid placed slightly lingually. The height of the crown is variable; the mesial wall of the anterior cuspid is procumbent. The tooth usually has two fused roots, often distinguished by a furrow on each side, being deeper labially than lingually. There are specimens with single roots (3 out of 31 ), double roots (7 out of 31 ) and with fused roots separated by a vertical furrow (21).

p3. This premolar is much larger than $\mathrm{p} 2$ but somewhat smaller and narrower than p4 (Pl. 1, Fig. 18, Pl. 3, Figs 9-11). It appears sub-triangular in side view. The crown is dominated almost exclusively by a high, slender, sub-conical cuspid (protoconid), a low cuspid situated on the anterior side (paraconid) and a strong and low rear cingulum, whose postero-lingual corner protrudes distally and may carry a small cuspule. The posterior basin is divided in two by a weak, blunt longitudinal crest, but less markedly than in $\mathrm{p} 4$. The rear face of the protoconid is flat and its tip is blunted by wear. The metaconid is absent. The occlusal profile of the tooth is sub-oval, with the posterior edge straight and postero-lingually oblique to the sagittal axis of the tooth. The tooth has two roots, well-separated from one another and with the posterior one slightly larger than the mesial one.

p4. The fourth lower premolar is larger and wider than p3 (Pl. 1, Fig. 19, Pl. 3, Figs 12-13) and has a welldeveloped trigonid; the tooth is therefore molarized. The central part of the tooth is dominated by a sharp and high protoconid, with a sub-conical metaconid which tends to be situated mesio-lingually to it. These two cuspids are joined by a crest (protocristid sensu Lopatin 2006). The anterior part of the tooth consists of a high paraconid that elongates posteriorly into a sharp paralophid; the latter is connected at an obtuse angle with the sharp anterior arm of the protoconid (preprotocristid) and with a carnassial notch in between. The tip of the well-defined metaconid is slightly inclined lingually. The three cuspids enclose a narrow trigonid basin, open lingually. Posteriorly, the tooth shows a short and shallow basin delimited by a strong cingulum, which first rises and then levels off sub-horizontally towards the distally-protruding postero-lingual corner; the latter sometimes carries a small accessory cuspid. As in p3, the posterior basin is divided into two unequal parts by a weak and blunt longitudinal crest. The tooth has two unequallysized roots, the posterior one being the larger. m1. The first lower molar is the largest of the lower cheek tooth row. (Pl. 1, Fig. 20, Pl. 3, Fig. 14) The protoconid is the highest cuspid; a paralophid issues from it anteriorly and bends lingually, ending into a swollen paraconid. The metaconid is conical and pointed, slightly lower than the protoconid from which it is separated by a notch. It is placed somewhat more anteriorly than the protoconid. A crescentshaped hypoconid is the lowest cuspid. The entoconid is large, sub-conical and somewhat lower than the metaconid. The posterior arms of the entoconid and hypoconid are fused, forming a sinuous crest (postcristid) that bounds, posteriorly, a deep talonid basin. The anterior arm of the hypoconid (crista obliqua) is low and ends against the posterior wall of the protoconid. The entocristid runs straight anteriorly reaching the distal wall of the metaconid, or joining a weak and low metacristid. The distal cingulid is weak, short and not fused with the postcristid. The antero-labial cingulid is narrow and bounds the base of the paralophid-paraconid complex; it disappears at the base of the protoconid.

m2. The second lower molar is smaller than $\mathrm{m} 1$ and less elongated mesio-distally. (P1. 1, Fig. 21, Pl. 3, Fig. 15). It has no paraconid. The paralophid is low and curves lingually and distally, almost closing the lingual opening of the trigonid basin. The crest is oriented more vertically, and the metaconid is placed in a more anterior position than in $\mathrm{m} 1$. Such an arrangement produces a comparatively shorter trigonid: in fact in $\mathrm{m} 2$, the trigonid is around $47 \%$ of the total length of the tooth, whereas it is $52 \%$ in $\mathrm{m} 1$. The antero-labial cingulid is stronger than in $\mathrm{m} 1$. A weak labial cingulid is often present in the valley between protoconid and hypoconid. The tip of the entoconid is placed slightly more mesially than the hypoconid. The posterior cingulid is similar to that of $\mathrm{m} 1$.

m3. This tooth is smaller than $\mathrm{m} 2$, but the two teeth share trigonids morphologically similar (P1. 1, Fig. 22, P1. 3, Fig. 16). The third lower molar differs from $\mathrm{m} 2$ by having shorter and narrower trigonid and talonid, with the talonid narrower than the trigonid. The crest-shaped paraconid is similar to that of $\mathrm{m} 2$. The entoconid is a strong cusp that protrudes distally more than in $\mathrm{m} 1$ and $\mathrm{m} 2$. Compared to $\mathrm{m} 2, \mathrm{~m} 3$ has a weaker hypoconid, situated more lingually and not protruding labially. The posterior cingulid is lacking.

Mandibles. The sample from BRS 25 includes a few fragmental horizontal rami without teeth. The specimens worth notice are:

- A fragmental right horizontal ramus with p1-m3 alveoli and the basal, anterior portion of the ascending ramus (MSF 3050). The mental foramen opens between the roots of $\mathrm{p} 4$.

-A fragment of a left horizontal ramus with p1-p4 alveoli and a broken mesial portion (MSF 3051). Based on the shape of the latter, p1 is single-rooted, p2 is single-rooted with root carved by a vertical groove. A large alveolus, presumably of the canine, occurs mesially to $\mathrm{p} 1$. Two cavities, possibly the alveoli of i1 and i2, are stretched under it. Based on comparisons with Parasorex socialis, the alveolus of i3 would be smaller and situated more dorsally than that of i2; hence, it cannot be excluded that it is not preserved. The mental foramen opens under the anterior root of $\mathrm{p} 4$.

- A fragmental left mandible with $\mathrm{p} 4-\mathrm{m} 2$, still included in the matrix, broken in front of $\mathrm{p} 4$ and with only part of 
Table 3. List of the mandible fragments not reported in the text.

\begin{tabular}{|l|l|l|}
\hline \multicolumn{1}{|c|}{ Preserved tooth } & \multicolumn{1}{|c|}{ Preserved alveoli } & \multicolumn{1}{|c|}{ Inventory numbers } \\
\hline none & $\mathrm{p} 3-\mathrm{p} 4$ & MZF 3055 \\
\hline $\mathrm{p} 3$ and the root of $\mathrm{p} 1$ & $\mathrm{p} 2$ & MZF 3056 \\
\hline $\mathrm{p} 4$ & $\mathrm{p} 3$ and the (?) distal alveolus of $\mathrm{p} 2$ & MZF 3057 \\
\hline $\mathrm{p} 4$ and a fragment of $\mathrm{p} 3$ & mesial root of the m1 & MZF 3058 \\
\hline none & $\begin{array}{l}\mathrm{p} 3-\mathrm{p} 4 \text { and the mesial alveolus of m1; two more alveoli are present mesially } \\
\text { to } \mathrm{p} \text {, which may belong to a one-rooted p1 and p2 or a two-rooted p2 }\end{array}$ & MZF 3059 \\
\hline mesial root of the p4 & $\begin{array}{l}\mathrm{p} 1-\mathrm{p} 2 \text { and distal alveolus of } \mathrm{p} 3 \text {; the pattern of the alveoli shows that the p2 } \\
\text { has a disto-mesially elongated, partially divided root, while the root of p1 is } \\
\text { single and rather small }\end{array}$ & MZF 3060 \\
\hline none & $\mathrm{p} 1-\mathrm{p} 3$ and mesial alveolus of $\mathrm{p} 4$ & MZF 3061 \\
\hline none & $\mathrm{m} 2-\mathrm{m} 3$ & MZF 3062 \\
\hline none & $\mathrm{p} 2-\mathrm{m} 1$ and the mesial alveolus of m2 & MZF 3063 \\
\hline
\end{tabular}

the ascending ramus preserved (MSF 3052). The anterior margin of the ascending ramus is fairly vertical. The mental foramen opens between the mesial and distal roots of $\mathrm{p} 4$.

- A fragment of right mandible still embedded in the matrix, with p3, p4 and a broken m2 (MSF 3053).

- A fragment of left mandible with the alveoli of p3 (still preserving the anterior root of the tooth), of a single-rooted $\mathrm{p} 2$ and of $\mathrm{p} 1$. The mental foramen opens between the mesial and distal roots of $\mathrm{p} 4$ (MSF 3054).

Other specimens are listed in Table 3.

Maxillary. Left maxillary fragment with P4-M2 (P1. 2, Fig. 20). The morphologies of the preserved teeth are included in the variability reported in the descriptions above.

\section{a}
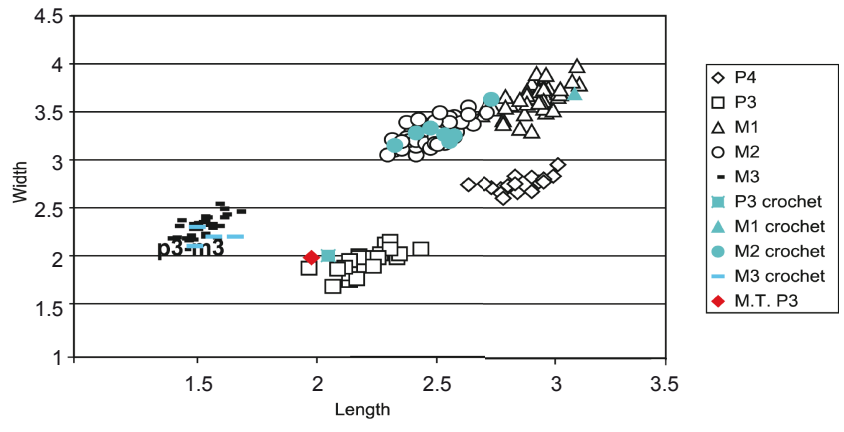

b
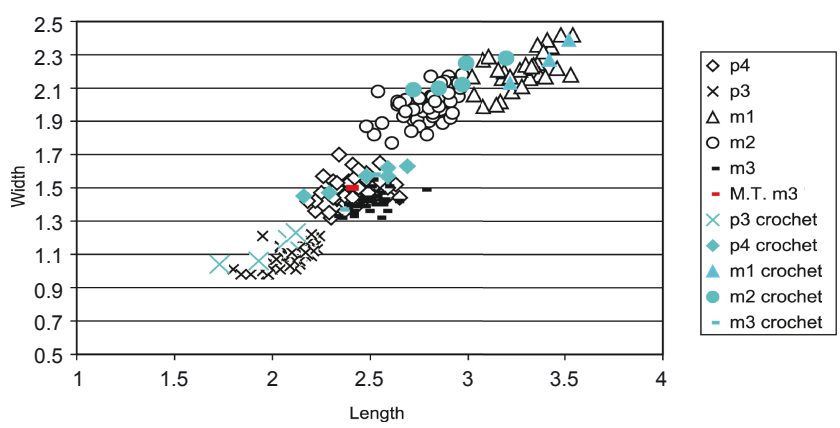

Text-fig. 3. Scatter diagrams of a) upper and b) lower teeth from BRS 25 (black profile), French localities (cyan; data from Crochet 1986) and Moncucco Torinese (red ones; unpublished data).

\section{Comparisons}

\section{Comparisons with the original material described by Crochet}

The analysis of the BRS 25 specimens permits to complete and partially amend Crochet's (1986) description of Parasorex depereti. The lingual lobe on the P3s from BRS 25 is more variable than reported by Crochet (1986). The lingual cusps are placed more anteriorly; in some specimens the hypocone is larger than the protocone; six have only one

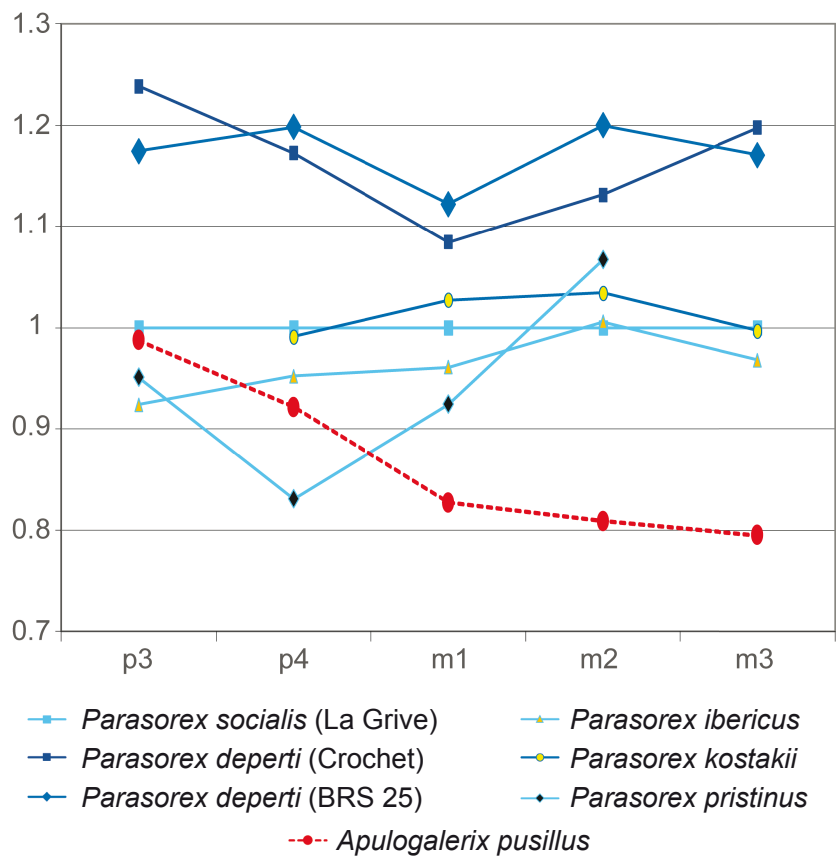

Text-fig. 4. Ratio diagrams of total length of p3-m3. Parasorex depereti from BRS 25 (data from Fanfani 1999), Parasorex depereti (data from Crochet 1986), Parasorex ibericus, type locality Otura-1, Spain (Mein and Martín-Suárez 1993), Parasorex pristinus (Ziegler 2003), Apulogalerix pusillus, Gargano (fissure filling F32), Italy (Masini and Fanfani 2013). On the horizontal axis are reported the element of the series, in ordinates the ratio of the average lengths on the standard Parasorex socialis from La Grive, France (data from Masini and Fanfani 2013). 
lingual hypocone. The labial cingulum is always present on the upper molars from BRS 25. The paracone and metacone are not located so labially in the BRS 25 specimens, and the protocone is placed somewhat more mesially with respect to the paracone (as occurs in most species of Parasorex). On the BRS $25 \mathrm{M} 1-2 \mathrm{~s}$, the protocone, hypocone and metaconule are variably connected with one another. In several cases, particularly on $\mathrm{M} 2 \mathrm{~s}$, the postprotocrista is imperfectly connected with the base of the metaconule.

The BRS 25 p2s have a weak anterior cuspid and show high morphological variability. The majority has anterior and posterior roots fused with a deep furrow in between; a few have divided roots, whereas single-rooted specimens are very rare. The scatter diagrams of Text-fig. 3 show that, besides being somewhat smaller, the BRS 25 specimens show minimum differences from than the French counterparts. The species therefore remains rather stable over time.

\section{Comparisons with $P$. kostakii}

P. kostakii (MN 4, Karydia, Greece) was described by Doukas and van den Hoek Ostende (2006) and ascribed to Galerix. It was later attributed to the genus Parasorex by Prieto et al. (2012), based on the presence of the paralophid on $\mathrm{p} 4$ and of the hypocone on P3. However, in a number of cases $(20 \%)$, the protocone and metaconule are connected on M2. The relative sizes of $\mathrm{p} 2$ and $\mathrm{p} 3$, which is a marker for discriminating the various genera (Van den Hoek Ostende 2001), are unfortunately unknown. $P$. depereti is larger than P. kostakii. The two species share M1-2s without mesostyles; moreover protocones and metaconules are rarely connected with one another $(20 \%$ are connected in P. kostakii, and about $22 \%$ in $P$. depereti). In the upper cheek teeth, $P$. depereti can be discriminated from $P$. kostakii by having P3-4s with larger linguo-distal lobe and P3s proportionally larger than $\mathrm{P} 4 \mathrm{~s}$, with lingual margin less oblique mesiolingually, with protocone located more anteriorly and with more lingually protruding hypocone. Differences can also be seen in the upper molars: $P$. depereti has shorter and wider ("less squarish") M1s, M1-2s with weaker and more discontinuous and often totally absent, labial cingula, M2s with more arched (concave) labial margin and M3s with weaker mesial cingulum. In the lower cheek teeth, compared with $P$. kostakii, $P$. depereti has $\mathrm{p} 4 \mathrm{~s}$ with higher paralophid and more open carnassial notch, blade-shaped paraconid connected with the apex of the protoconid via a sharp and "complete" paralophid (in P. kostakii only one specimen has a complete paralophid; in other specimens the preprotocristid is absent and the anterior margin of the protoconid is rounded), metaconid always present, well-developed and prominent lingually (in P. kostakii it may be variably developed or even absent), m1s proportionally shorter than the teeth next to it, with trigonid more closed lingually (short trigonid) and with hypoconid more prominent labially, m1-2s without labial cingulum and with rear cingulum weaker and separated from the postcristid and $\mathrm{m} 1-\mathrm{m} 3 \mathrm{~s}$ with weaker antero-labial cingulum.

\section{Comparisons with $P$. pristinus}

Parasorex pristinus (MN 5, Mülbach am Manhartsberg, Austria; Ziegler 2003) had first been attributed to the genus
Schizogalerix based on the (supposed) presence of an initial splitting of the mesostyle on M1-2 (Ziegler 2005). It was interpreted as the oldest and more primitive representative of the genus so far found. Later, an older but more derived species of Schizogalerix was found in Anatolia ( $S$. evae, Sabuncubeli, MN 3; De Bruijn et al. 2007). This find led Doukas and van den Hoek Ostende (2006) to conclude that including the moonrat from Mülbach in Schizogalerix is less parsimonious than assigning it to the genus Parasorex (De Bruijn et al. 2007). The upper premolars of $P$. pristinus are too heavily damaged to be used for comparisons. Morphologically, $P$. depereti can be discriminated from P. pristinus by being larger, by having M1-2s with weaker paraconule, and straight, non-sinuous mesostyle. Like in $P$. depereti, some specimens have a weak crest connecting the protocone-hypocone junction with the metaconule (triple connection). P. depereti normally appears having M2s somewhat narrower and squarish in outline (Pl. 1, Fig. 10, Pl. 2, Figs 22-25), and M3 with metaconule poorly developed or completely absent. Compared with P. pristinus, the upper molars have weaker or absent mesial and distal cingula.

Comparing the lower dentition of the two species, one notices that $P$. depereti has a longer 44 with higher paralophid, more open carnassial notch, blade-shaped paraconid, and sharp and "complete" paralophid (i.e. extended from the paraconid to the apex of the protoconid). The trigonid is more closed lingually (shorter trigonid) on $\mathrm{m} 1$, and the antero-labial cingulum is weaker on $\mathrm{m} 1-\mathrm{m} 3 \mathrm{~s}$. The labial cingulum is well-developed on the $\mathrm{m} 1-2 \mathrm{~s}$ of $P$. pristinus, and absent on those of $P$. depereti; the posterior cingulum is variably developed on the $\mathrm{m} 1-\mathrm{m} 2 \mathrm{~s}$ of $P$. pristinus, whereas it is weak and separated from the postcristid on those of $P$. depereti.

The small number of remains of $P$. pristinus renders proportional comparisons difficult. The pattern of its lower dentition differs from those of the other species of the genus by having a large $\mathrm{m} 2$ and $\mathrm{m} 1$, and $\mathrm{p} 4$ strongly decreasing in size.

\section{Comparisons with $P$. socialis}

Parasorex socialis is the best documented species of the genus; it was selected type species of the genus. It was distributed from Spain to central Europe, and ranged in time from MN 6(?) to MN 8-10 (Petersbuch 68, Barranc de Can Vila 1, Steinheim, La Grive, Anwil, etc.; Prieto and Rummel 2009, Furió et al. 2011). Besides observing that Parasorex socialis is smaller than $P$. depereti, Crochet (1986) remarked that the two species share a number of characters (relatively large $\mathrm{P} 4 \mathrm{~s}$, protocone and hypocone connected by an uninterrupted crest on M1-2s, a lingual lobe on P3 holding two cusps and the distal crest of the metaconule elongated to the disto-labial corner of M1-2s). Van den Hoek Ostende (2001) claimed that the morphologies indicated by Crochet (1986) are typical traits of the genus Parasorex.

Parasorex depereti can be discriminated from $P$. socialis in possessing P3 in some cases bearing only a single lingual cusp, P3 and P4 with lingual lobe more developed distally (Crochet 1986), hypocone relatively higher on P4, more squarish $\mathrm{M} 1-2 \mathrm{~s}$, hypocone more separated from the protocone on $\mathrm{M} 1-\mathrm{M} 2$ and connected with the posterior 
arm of the protocone by a lower and weaker prehypocrista. $P$. depereti also shows a greater proportion of M1-2s in which the posterior arm of the protocone is connected both with the mesial arm of the hypocone and with the metaconule (triple connection in Borrani et al. 2017), and M2 in which the hypocone-protocone connection is very low and weak. $P$. depereti differs in having a straight mesostylar crest on M1-2, with a deep notch situated halfway between paracone and metacone, metaconid of $\mathrm{p} 4$ more robust and prominent lingually. On m1-2 the posterior cingulum is short, situated lower and not connected with the posterior arm of the entoconid as sometimes occurs in P. socialis.

In the high variability of the BRS sample, other differences can be noted between $P$. depereti and $P$. socialis. The two cusps on the lingual lobe of $\mathrm{P} 3 \mathrm{~s}$ are located more mesially in the BRS 25 specimens than in P. socialis, and the hypocone is either sub-equal or slightly larger than the protocone; in the $\mathrm{P} 3 \mathrm{~s}$ of $P$. socialis, the protocone is constantly larger than the hypocone. There are also BRS 25 $\mathrm{P} 3 \mathrm{~s}$ with no protocone, or with protocone reduced to a small bulge at the base of the paracone. BRS 25 specimens also differ from $P$. socialis in having upper molars with small protoconule, protocone with high anterior and posterior arms (especially on M2s) and very large M3s. The M1s from BRS also have an oblique labial border in the metastylar region, generated by the greater elongation of the metastylar crest, and M2s with concave labial border; the labial borders of the upper molars of $P$. socialis tends to be straighter than those of $P$. depereti. Moreover, weak labial cingula are present on M1-2s from BRS 25 and are absent on those described by Crochet (1986). In contrast Parasorex socialis has strong cingula. Crochet (1986) reported a slight lingual displacement of para- and metacone with respect to $P$. socialis; this feature is unclear on the BRS 25 specimens, likely because of the occurrence of the labial cingulum. BRS specimens can also be discriminated from equivalent ones of $P$. socialis by having higher and proportionally longer $\mathrm{p} 4$, and mental foramen invariably under $\mathrm{p} 4$. The mesial cuspid is weak or even absent on the p2s from BRS 25, and is always robust on the $\mathrm{p} 2 \mathrm{~s}$ of $P$. socialis. The roots of $\mathrm{p} 2$ are fused in $P$. depereti and separated in $P$. socialis.

\section{Comparisons with $P$. ibericus}

Parasorex ibericus also shares several features with $P$. socialis and $P$. depereti. It was first described by Mein and Martín-Suárez (1993) based on material from Spanish localities, ranging in age from $\mathrm{MN} 10$ to $\mathrm{MN} 13$. It is essentially a Parasorex socialis-like gymnure, characterised by the loss of i3, and by having shorter muzzle and shorter premolars.

$P$. ibericus differs from $P$. depereti in having lost i1 and in possessing shorter premolars, particularly p3, and in having proportionally longer molars, particularly M2 and $\mathrm{m} 2$. P. ibericus also differs in the variably-shaped and sometimes partially divided mesostyles on M1-2s, in the posthypocrista that is often merged with the posterior cingulum on M1s, and in having short and weak anterior and posterior cingula in M1-2, weaker than those of $P$. depereti. The protocone, metaconule and hypocone are rarely joined (triple connection) in P. ibericus, whereas they are more frequently so in $P$. depereti. The Spanish taxon has two-rooted p2, but only in the oldest known populations; Turolian representatives of the species have single-rooted $\mathrm{p} 2 \mathrm{~s}$; the posterior cingulid in $\mathrm{m} 1-2$ is short and low, like that of $P$. depereti.

\section{Comparison with Apulogalerix}

Apulogalerix is an endemic Gargano moonrat. Masini and Fanfani (2013) considered it an offshoot from Parasorex ibericus. For this reason, it is here compared with $P$. depereti.

Apulogalerix underwent marked changes in the premolar series (cuspid bulge, morphological simplification of P3 and p4, enlarged premolars relative to molars - Text-fig. 4). The second and third molars tend to grow progressively larger in $P$. depereti, and smaller in Apulogalerix. The hypocone on the P3s of Apulogalerix is reduced or absent, whereas some P3s of Parasorex depereti have an unicuspidate inner lobe as a consequence of the reduction or disappearance of the protocone. The $\mathrm{p} 4$ of Apulogalerix differs from that of $P$. depereti: it is a massive, trigonid-less unicuspidate tooth, with metacone merged with the protocone, low, tubercular paracone and no paracristid. Compared with those of Apulogalerix, the upper molars of $P$. depereti have a rather "primitive" (i.e. Galerix stehlini/exilis-like) pointed hypocone, a low anterior arm of the hypocone on M1s and $\mathrm{M} 2 \mathrm{~s}$ relative to the posterior arm of the protocone, a higher frequency of M1-2 with triple connection, and very rare M2 with low and weak hypocone-protocone connection. The mesostylar region (centrocrista) of M1-2 is straight and deeply incised in $P$. depereti; it is very variable and sometimes divided in Apulogalerix. Moreover, $P$. depereti has p2 with fused roots, whereas in Apulogalerix the tooth has separated roots.

\section{Ratio diagrams}

Unlike BRS 25, which was collected from an individual karstic fissure filling, the sample studied by Crochet (1986) includes specimens from various localities and of different ages. The representatives of both samples are the largest Parasorex known so far.

The patterns of the French and BRS 25 lower teeth shown in Text-fig. 4 are similar to one another in the p4-m2 sections, although the ones in Crochet's sample are somewhat larger than the ones from BRS 25. In contrast, the p3 and $\mathrm{m} 3$ values from the French sample are a little smaller than the equivalent teeth from BRS 25. The p3s studied by Crochet (1986) come from three different localities; their low mean value is due to a very small tooth $(1.73 \times 1.04)$ from Celleneuve. The $\mathrm{m} 3 \mathrm{~s}$ in the French sample are only two, and each one comes from a different locality. It is likely that the small number of specimens of the French sample has a bearing on the differences in the proportions of these two teeth.

Compared with the patterns shown by the teeth of $P$. socialis, those of $P$. depereti show a strong reduction in the size of $\mathrm{m} 1$ with respect to those of $\mathrm{p} 4$ and $\mathrm{m} 2$. In contrast, $P$. ibericus shows a marked reduction of $\mathrm{m} 1$ and of the premolars. The P. kostakii sample includes teeth not too different in size and proportions from those of the standard 
(P. socialis). In contrast, the pattern of the few specimens of $P$. pristinus stands out for very large $\mathrm{m} 2$ and $\mathrm{p} 3$ and an evident, progressive reduction of $\mathrm{m} 1$ and $\mathrm{p} 4$ in between. Should these differences be confirmed by further finds, P. pristinus would be distinguished for being quite separated from all the other species.

\section{Discussion}

In spite of their older age, the BRS 25 specimens share many morphological traits with the French counterparts on which Parasorex depereti was first described. For this reason, the BRS 25 material can confidently be assigned to P. depereti.

Based on a general tendency towards the reduction of the dental cingula, the BRS 25 specimens would result in being somewhat more primitive than the French representatives, because they retain weak labial cingula in their upper molars. Other characters that change over time are the roots of the second lower premolar, as already observed by Borrani et al. (2017). The roots of these teeth fuse in the distinct evolutionary lines that lead to Parasorex ibericus and to P. depereti itself. The French material includes only two p2s, one with two separate roots, the other with fused roots. Most of the p2s from BRS 25 have fused roots, but there are also some with separate roots and a few that are single-rooted. This confirms that roots progressively tend to fuse in this species over time.

Whether i3 is present or not in P. depereti is still an unsettled question. The third is the smallest of the lower incisors in Galericini. It tends to grow very small in Schizogalerix, and becomes tiny or disappears entirely in still other Parasorex species, such as Parasorex ibericus. Also the endemic Apulogalerix pusillus has lost the third lower incisor. Direct comparison of $P$. depereti from Brisighella with $P$. socialis from La Grive did not exclude the occurrence of $i 3$ in the BRS 25 sample. The jawbones are very poorly preserved in the rostral region, with the sole exception of one specimen that still preserves part of the alveoli in front of the canine. In P. socialis, the i3 is smaller than i2, and can be either aligned with the other teeth, or more frequently, placed labially. Only a mandible with a well-preserved rostral portion can demonstrate if this tooth is still present or not in $P$. depereti.

The relatively high frequency of crests joining the protocone to both hypocone and metaconule, and the occurrence of very low and weak anterior arm of the hypocone, distinguish $P$. depereti from the other Late Miocene representative of Parasorex. We suggest, however, that these morphological traits can be considered as a convergence rather than preserved primitive characters. Actually this feature occurs in a species that is morphologically derived for several other aspects. The absence of connection between protocone and metaconule was included in the diagnostic traits of genus Parasorex by the pioneering work of Van den Hoek Ostende (2001); however, the findings of new species and a more careful inspection of Parasorex upper molars demonstrated that also this character is subject to variation. A so-called "triple connection" (Borrani et al. 2017) is a part of the morphological variability of Parasorex, and actually occurs at a different rate, in almost all the species of the genus. However, as in Parasorex depereti, it is never so clearly marked as in older species of genus Galerix.

The P3 of Parasorex is most subjected to evolutionary change. Hence, the occurrence of two lingual cusps on P3 cannot be considered a character of strong diagnostic significance. Worth noting is that the inner lobe of P3 modified independently in two separate lineages during the Late Miocene. In Apulogalerix, which is an endemic offshoot of Parasorex, the hypocone of $\mathrm{P} 3$ was lost as a consequence of the simplification and bulging of the lower fourth premolar. On some of the P3s of the non-endemic, continental species $P$. depereti, the hypocone replaces the protocone, which disappears or migrates mesially, at the very anterior margin of the crown, becoming a small, residual cusp, stuck against the base of the paracone. This leads to the development of a large, flat platform at the lingual distal corner of the crown. The antagonist of P3, i.e. the trigonid of $\mathrm{p} 4$, is well-developed in $P$. depereti; it has a high, sharp, functional trigonid, with no sign of reduction or simplification. The modifications undergone by the premolars of Apulogalerix are interpreted as an adaptation to carnivory, for feeding on prey with hard exoskeleton or on shelled continental molluscs (Masini and Fanfani 2013), partially reversing the more omnivorous adaptation of $P$. socialis-ibericus. In contrast, the morphofunctional significance of the dental features of $P$. depereti is still unclear. Still in the light of the morpho-functional interpretation of the teeth of Galericini given by Van den Hoek Ostende (2001), P. depereti also could have been a species which, in analogy with Apulogalerix, abandoned the omnivorous adaptation of Parasorex, Schizogalerix and other Schizogalerix-like species in favor of a different, more carnivorous diet. The absence of bulging of the premolars, the very pointed $\mathrm{p} 3$ and the sharp cutting edge of $\mathrm{p} 4$ however, may indicate a more generalist diet on invertebrates, but less specialized than that supposed for Apulogalerix.

\section{Conclusions}

Parasorex depereti and P. ibericus are presently the two most recent species of the genus. P. ibericus seems to have adaptations similar to those of Schizogalerix in the enlargement of the molars, particularly $\mathrm{M} 2$, in the variability of the mesostyle, which is often divided, in the posthypocrista, which is fused to the posterior cingulum and in the robust connection between the mesial arm of the hypocone and the rear one of the protocone on M1-2s.

$P$. depereti seems to follow a different evolutionary pattern. The mesostyle is absent, the posterior cingulum is weak, its connection with the posterior arm of the hypocone is rare, that between the hypocone and the rear arm of the protocone is weak, the premolars are not reduced - in contrast, $\mathrm{p} 4$ is large and has a sharp trigonid, M1 and $\mathrm{m} 1$ do not grow larger and M2 is more squarish.

The two taxa independently evolved a tendency towards the fusion and reduction of the roots of p2, and towards reduction of the cingula; in the most advanced representatives of the species, M1-2s lose the labial cingulum. The two species differ in size and in the morphology of P4 and of P3 in particular; the latter in $P$. depereti can sometimes have only one cusp on the lingual lobe (hypocone). 
These differences rule out a direct descendance of $P$. depereti from $P$. ibericus. $P$. depereti appears closer to $P$. socialis, which is less specialized than $P$. ibericus and of $P$. depereti itself. In spite of the weak anterior arm of the hypocone and of the presence of a connection between the crest joining the protocone and hypocone with the metaconule (triple connection) that confer a more primitive aspect to $P$. depereti, all the other features are shared with $P$. socialis or are possibly derived from characters possessed by the latter.

The possibility that $P$. depereti originated from a still unknown species close to $P$. socialis seems to be gaining strength. This imposes that during the late Late Miocene, there were at least two distinct lineages of Parasorex, which indicates that the evolution and the specific abundance of this genus at that time are still known imperfectly.

\section{Acknowledgements}

This research was financially supported by PRIN (Research Projects of National Interest) 2009 MIUR (Ministry of Education, University and Research) grants. We wish to thank Marco Sami and Giampaolo Costa, who were collaborators of the Malmerendi Museum of Faenza at the time of the discovery, and Antonio "Tonino" Benericetti, who discovered the vertebrates at Monticino Quarry and collected many of the fossils.

\section{References}

Abbazzi, L., Benvenuti, M., Ceci, M. E., Esu, D., Faranda, C., Rook, L., Tangocci, F. (2008): The end of the Lago-Mare time in the SE Valdelsa Basin (Central Italy): interference between local tectonism and regional sea-level rise. - Geodiversitas, 30(3): 611-639.

Antunes, M. T., Mein, P. (1989): Petit mammifères du Miocène terminal du bassin de Alvalade (Portugal); comparaisons avec des faunes de l'Espagne et du Maghreb. Bollettino della Società Paleontologica Italiana, 28(2-3): 161-170.

Borrani, A., Savorelli, A., Masini, F., Mazza, P. P. A. (2017): The tangled case of Deinogalerix (Late Miocene endemic erinaceid of Gargano) and Galericini (Eulipotyphla, Erinaceidae): a cladistic perspective. - Cladistics, 34(5): 542-561. https://doi.org/10.1111/cla.12215

Costa, G. P., Colalongo, M. L., De Giuli, C., Marabini, S., Masini, F., Torre, D., Vai, G. B. (1986): Latest Messinian vertebrate fauna preserved in a paleokarst-neptunian dyke setting. - Le Grotte d'Italia, 12(4): 221-235.

Crochet, J. Y. (1986): Insectivores Pliocènes du sud de la France (Languedoc-Roussillon) et du nord-est de l'Espagne. - Palaeovertebrata, 16(3): 145-171.

De Bruijn, H., Mayda, S., van den Hoek Ostende, L., Kaya, T., Saraç, G. (2006): Small mammals from the Early Miocene of Sabuncubeli (Manisa, S.W. Anatolia, Turkey). - Beiträge zur Paläontologie, 30: 57-87.

De Giuli, C. (1989): The Rodents of the Brisighella latest Miocene fauna. - Bollettino della Società Paleontologica Italiana, 28(2-3): 197-212.
De Giuli, C., Masini, F., Torre, D. (1988): The mammal fauna of Monticino Quarry. - In: De Giuli, C., Vai, G. B. (eds), Fossil Vertebrates in the Lamone Valley, Romagna Appennines, Field Trip Guidebook. Università di Bologna, Università di Firenze, Comune di Faenza, Faenza, pp. 65-69.

Doukas, C. S., van den Hoek Ostende, L. W. (2006): Insectivores (Erinaceomorpha, Soricomorpha; Mammalia) from Karydia and Komotini (Thrace, Greece; MN 4/5). - Beiträge zur Paläontologie, 30: 109-131.

Fanfani, F. (1999): Revisione degli Insettivori tardo neogenici e quaternari dell'Italia Peninsulare [Review of the Late Neogene and Quaternary insectivores from the Italian Peninsula]; Ph.D. thesis. - MS, DST, University of Modena, $282 \mathrm{pp}$. (in Italian) (copy in personal library of Federico Masini)

Fischer [de Waldheim], G. (1814): Zoognosia tabulis synopticis illustrata. Volumen tertium: Quadrupedum reliquorum, Cetorum et Monotrymatum descriptionem continens. - Typis Nicolai Sergeidis Vsevolozsky, Mosquae [Moscow], XXIV + 732 pp.

Furió, M., Angelone, C. (2010): Insectivores (Erinaceidae, Soricidae, Talpidae; Mammalia) from the Pliocene of Capo Mannu D1 (Mandriola, central-western Sardinia, Italy). - Neues Jahrbuch für Geologie und Paläontologie, Abhandlungen, 258(2): 229-242. https://doi.org/10.1127/0077-7749/2010/0100

Furió, M., Casanovas-Vilar, I., Moyà-Solà, S., Köhler, M., Galindo, J., Alba, D. M. (2011): Insectivores (Eulipotyphla; Mammalia) from the Middle Miocene of Barranc de Can Vila 1 (Vallès-Penedès Basin, Catalonia, Spain). - Geobios, 44(2-3): 199-213.

Gregory, W. K. (1910): The Orders of Mammals. - Bulletin of the American Museum of Natural History, 27: 1-524. https://doi.org/10.1016/j.geobios.2010.10.002

Linnaeus, C. (1758): Systema naturae per regna tria naturae, secundum classes, ordines, genera,species, cum characteribus, differentiis, synonymis, locis. Tomus I. Editio decima, reformata. - Impensis direct. Laurentii Salvii, Holmiae [Stockholm], 823 pp. https://doi.org/10.5962/bhl.title.542

Lopatin, A. V. (2006): Early Paleogene insectivore mammals of Asia and establishment of the major groups of Insectivora. - Paleontological Journal, 40(3): 205-405. https://doi.org/10.1134/S0031030106090012

Marabini, S., Vai, G. B. (1989): Geology oft he Monticino Quarry, Brisighella, Italy. Stratigraphic implications of ist late Messinian mammal fauna. - Bollettino della Società Paleontologica Italiana, 28(2-3): 369-382.

Masini, F. (1989): Prolagus sorbinii n. sp., a new Ochotonid (Mammalia, Lagomorpha) from the Messinian of Italy. Bollettino della Società Paleontologica Italiana, 28(2-3): 295-306.

Masini, F., Fanfani, F. (2013): Apulogalerix pusillus nov. gen., nov. sp., the small-sized Galericinae (Erinaceidae, Mammalia) from the "Terre Rosse" fissure filling of the Gargano (Foggia, South-Eastern Italy). - Geobios, 46(1-2): 89-104. https://doi.org/10.1016/j.geobios.2012.10.008

Masini, F., Rook, L. (1993): Hystrix primigenia (Mammalia, Rodentia) from the Late Messinian of the Monticino gypsum quarry (Faenza, Italy). - Bollettino della Società Paleontologica Italiana, 32(1): 79-87. 
Masini, F., Thomas, H. (1989): Samotragus occidentalis n. sp., a new bovid from the late Messinian of Italy. Bollettino della Società Paleontologica Italiana, 28(2-3): 307-316.

Mein, P., Martín-Suárez, E. (1993): Galerix iberica sp. nov. (Erinaceidae, Insectivora, Mammalia) from the Late Miocene and Early Pliocene of the Iberian Peninsula. Geobios, 26(6): 723-730. https://doi.org/10.1016/S0016-6995(93)80055-V

Meyer, C. E. H. von (1865): [Briefe an den Herausgerber]. Neues Jahrbuch für Mineralogie, Geologie und Paläontologie, 1865: 215-221.

Pomel, A. (1848): Etudes sur les Carnassiers Insectivores (extrait): Seconde partie, Classification des Insectivores. Archives des Sciences Physiques et Naturelles, 9: 244257.

Prieto, J., Rummel, M. (2009): Erinaceidae (Mammalia, Erinaceomorpha) from the Middle Miocene fissure filling Petersbuch 68 (southern Germany). - Zitteliana, 48/49: 103-111.

Prieto, J., Gross, M., Böhmer, C., Böhme, M. (2010): Insectivores and bat (Mammalia) from the late Middle Miocene of Gratkorn (Austria): biostratigraphic and ecologic implications. -Neues Jahrbuch für Geologie und Paläontologie, Abhandlungen, 258(1): 107-119. https://doi.org/10.1127/0077-7749/2010/0088

Prieto, J., van den Hoek Ostende, L. W., Hír, J. (2012): The Middle Miocene insectivores from Sáamsonháza 3 (Hungary, Nógrád County): Biostratigraphical and palaeoenvironmental notes near to the Middle Miocene Cooling. - Bulletin of Geosciences, 87(2): 227-240. https://doi.org/10.3140/bull.geosci.1296
Simpson, G. G. (1941): Large Pleistocene felines of North America. - American Museum Novitates, 1136: 1-27.

Torre, D. (1989): Plioviverrops faventinus n. sp., a new carnivore of late Messinian age. - Bollettino della Società Paleontologica Italiana, 28(2-3): 323-327.

Van den Hoek Ostende, L. W. (2001): A revised generic classification of the Galericini (Insectivora, Mammalia) with some remarks on their palaeobiogeography and phylogeny. - Geobios, 34(6): 681-695. https://doi.org/10.1016/S0016-6995(01)80029-2

Waddel, P. J., Okada, N., Hasegawa, M. (1999): Towards resolving the interordinal relationships of placental mammals. - Systematic Biology, 48(1): 1-5. https://doi.org/10.1093/sysbio/48.1.1

Ziegler, R. (1983): Odontologische und osteologische Untersuchungen an Galerix exilis (Blainville) (Mammalia, Erinaceidae) aus dem miozänen Ablagerungen von Steinberg und Goldberg im Nördlinger Ries (Süddeutschland); Ph.D. thesis. - MS, Ludwig-MaximiliansUniversität, München, Germany, 244 pp (copy in personal library of Federico Masini).

Ziegler, R. (2003): Insektenfresser (Lipotyphla) aus dem Mittel-Miozän von Mühlbach am Manhartsberg und Grund, Niederösterreich. - Annalen des Naturhistorischen Museums in Wien, Serie A für Mineralogie und Petrographie, Geologie und Paläontologie, Anthropologie und Prähistorie, 104: 251-265.

Ziegler, R. (2005): Erinaceidae and Dimylidae (Lipotyphla) from the Upper Middle Miocene of South Germany. Senckenebergiana lethaea, 85(1): 131-152. https://doi.org/10.1007/BF03043423 


\section{Explanations to the plates}

\section{PLATE 1}

Compiled upper dental series of $P$. depereti from BRS 25

1. I1 MSF 2725.

2. I2 MSF 2755.

3. I3 MSF 2796.

4. C MSF 2805.

5. P1 MSF 2825.

6. P2 MSF 2850.

7. P3 MSF 2870.

8. P4 MSF 2895.

9. M1 MSF 2920

10. M2 MSF 2965.

11. M3 MSF 3025.

Compiled lower dental series of $P$. depereti from BRS 25

12. i1 MSF 2401.

13. i2 MSF 2425.

14. ?i3 MSF 2450.

15. c MSF 2471.

16. p1 MSF 2491.

17. p2 MSF 2500.

18. p3 MSF 2515.

19. p4 MSF 2563.

20. $\mathrm{m} 1 \mathrm{MSF} 2616$.

21. m2 MSF 2647.

22. m3 MSF 2694.

Scale bars $2.5 \mathrm{~mm}$.

\section{PLATE 2}

Upper teeth of $P$. depereti from BRS 25

1. I1 MSF 2727, in labial view.

2. ?I2 MSF 2759, in labial view.

3. ?I3 MSF 2800, in labial view.

4. Right C1 MSF 2808, in a) occlusal, b) labial and c) lingual view.

5. Right C1 MSF 2809, in a) occlusal, b) labial and c) lingual view.

6. Right P2 MSF 2855, in a) occlusal, b) labial and c) lingual view.

7. Right C1 MSF 2810, in a) occlusal, b) labial and c) lingual view.

8. Left P2 MSF 2856, in a) occlusal, b) labial and c) lingual view.

9. Left P3 MSF 2873, in a) occlusal and b) lingual view.

10. Right P3 MSF 2874, in occlusal view.

11. Right P3 MSF 2875, in occlusal view.

12. Left P3 MSF 2876, in a) occlusal and b) lingual view.

13. Right P4 MSF 2896, in occlusal view.

14. Right P4 MSF 2897, in occlusal view.

15. Left P4 MSF 2895, in a) occlusal and b) distal view.

16. Right P4 MSF 2890, in occlusal view.

17. Right M1 MSF 2910, in occlusal view.

18. Right M1 MSF 2911, in occlusal view.

19. Left M1 MSF 2912, in occlusal view.
20. Fragment of maxillary (MSF 3064) with P4-M2, in occlusal view.

21. Left M1 MSF 2925, in occlusal view.

22. Left M2 MSF 2950, in occlusal view.

23. Right M2 MSF 2951, in occlusal view.

24. Right M2 MSF 2955, in occlusal view.

25. Left M2 MSF 2960, in a) occlusal and b) mesial view.

26. Right M3 MSF 3020, in a) occlusal and b) mesial view.

27. Right M3, MSF 3021, in occlusal view.

28. Right M3 MSF 3030, in occlusal view.

Scale bar $2.5 \mathrm{~mm}$. Drawings by F. Fanfani.

\section{PLATE 3}

Lower teeth of $P$. depereti from BRS 25

1. Left i1 MSF 2405, in a) dorsal and b) labial view.

2. Left i2 MSF 2430, in a) labial and b) lingual view.

3. Right ?i3 MSF 2460, in a) labial and b) lingual view.

4. Left c1 MSF 2475, in a) labial and b) lingual view.

5. Reversed right $\mathrm{p} 1 \mathrm{MSF} 2495$, in a) labial and b) lingual view.

6. Left p2 MSF 2505, in a) occlusal, b) labial and c) lingual view.

7. Left p2 MSF 2506, in a) occlusal, b) labial and c) lingual view.

8. Reversed right $\mathrm{p} 2 \mathrm{MSF} 2510$, in a) occlusal, b) labial and c) lingual view.

9. Left p3 MSF 2520, in a) occlusal, b) lingual and c) labial view.

10. Left p3 MSF 2522, in a) occlusal, b) lingual and c) labiall view.

11. Left p3 MSF 2525, in a) occlusal, b) lingual and c) labial view.

12. Left p4 MSF 2570, in a) occlusal, b) lingual, c) labial, d) distal and e) mesial view.

13. Left p4 MSF 2575, in a) occlusal, b) lingual, c) labial, d) distal and e) mesial view.

14. Left m1 MSF 2620, in a) occlusal, b) lingual and c) labial view.

15. Left $m 2$ MZF 2660, in a) occlusal, b) lingual and c) labial view.

16. Left m3 MSF 2695, in a) occlusal, b) lingual and c) labial view.

Scale bar $2.5 \mathrm{~mm}$. Drawings by F. Fanfani. 
PLATE 1
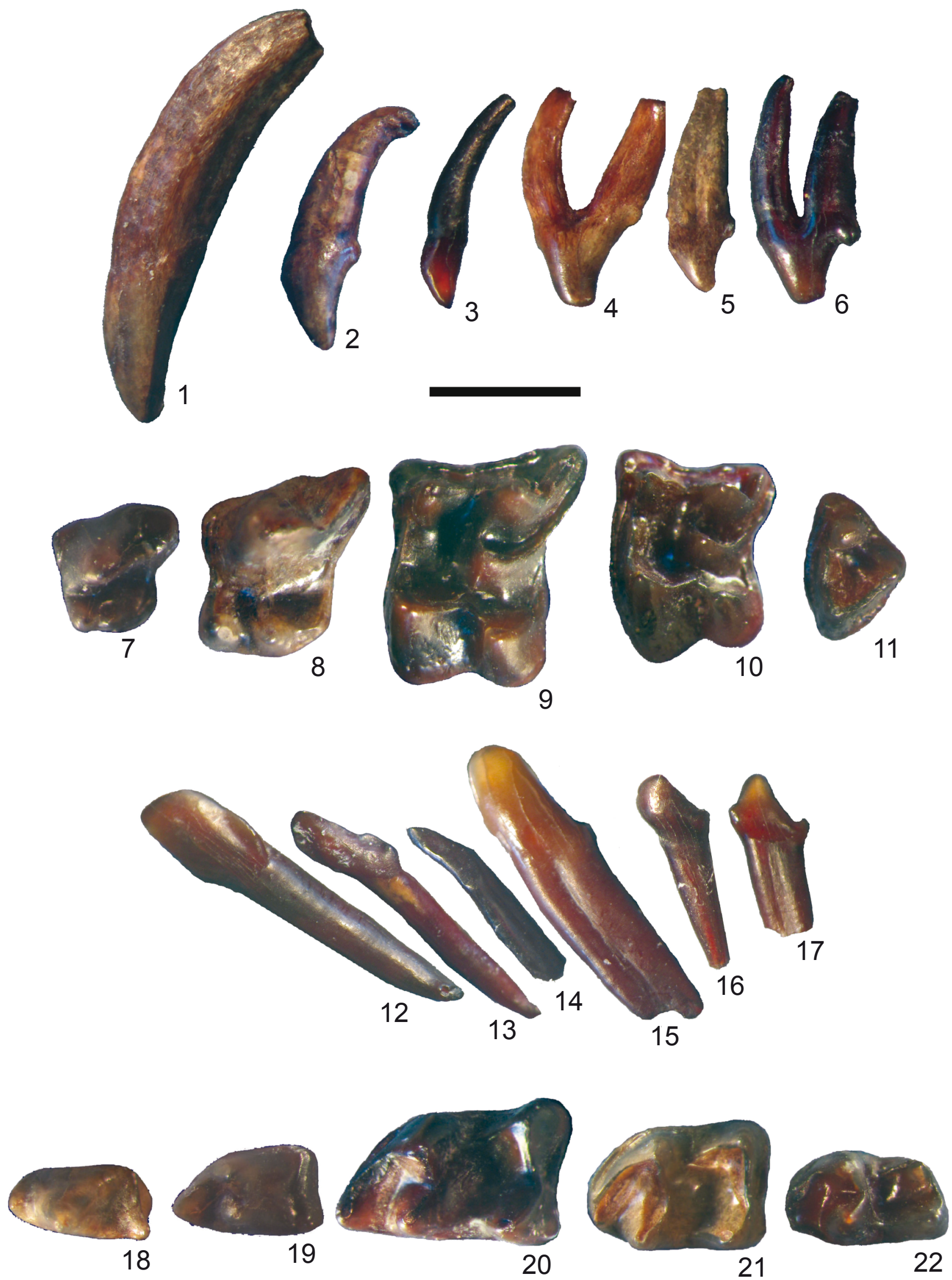
PLATE 2

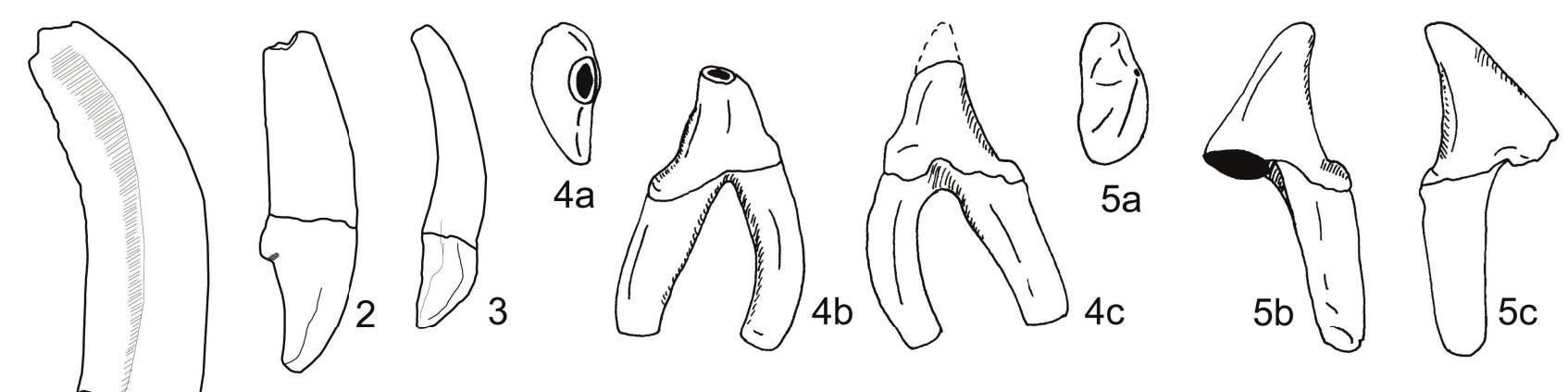

2
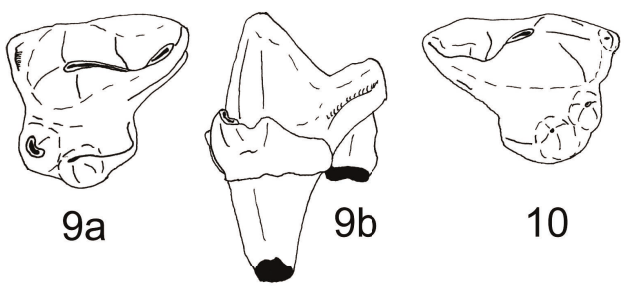

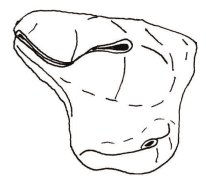

11

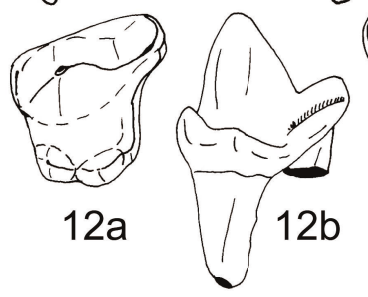

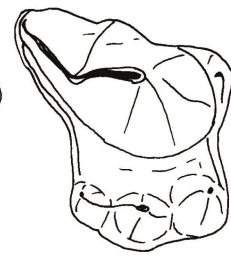

13
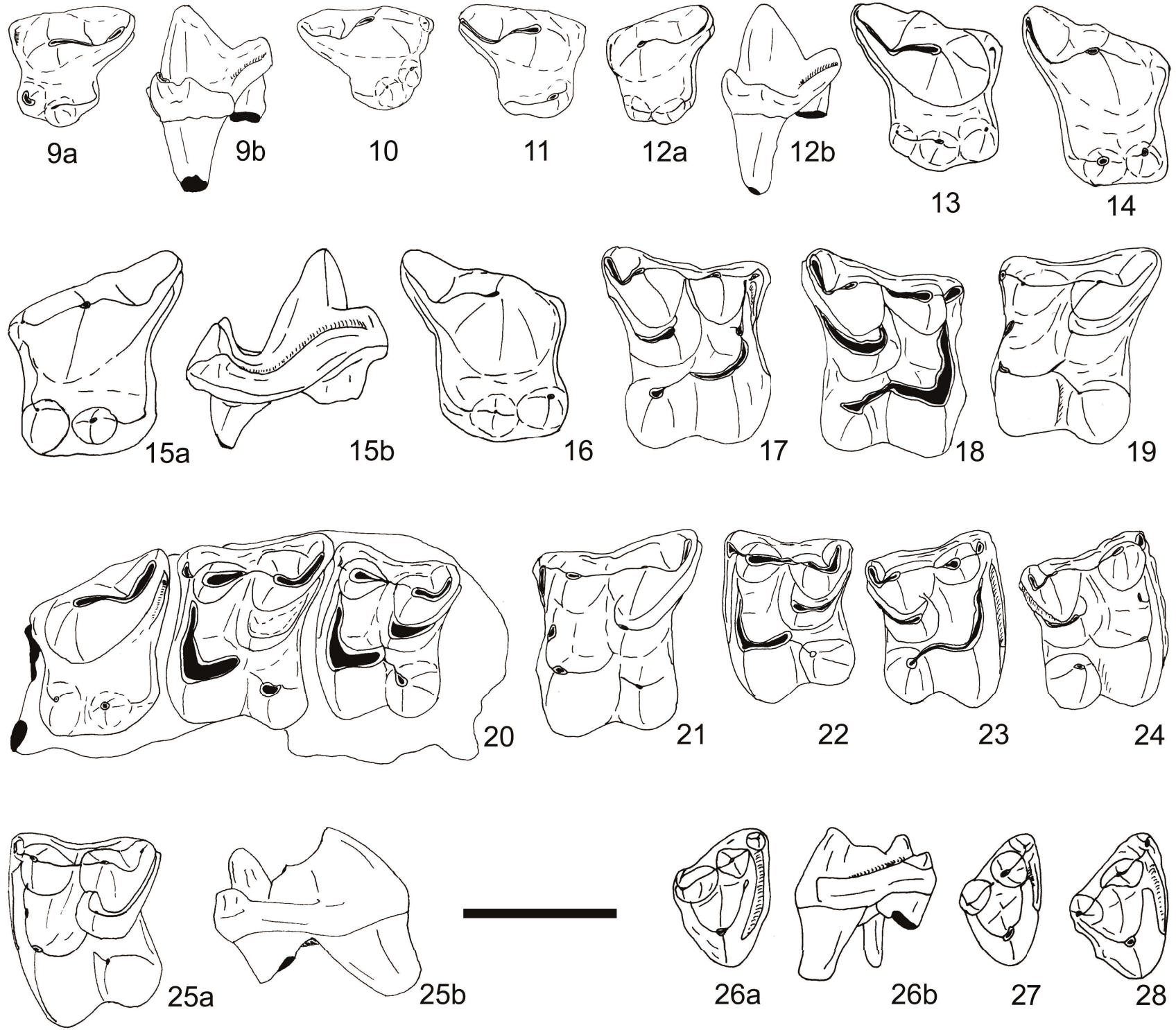


\section{PLATE 3}
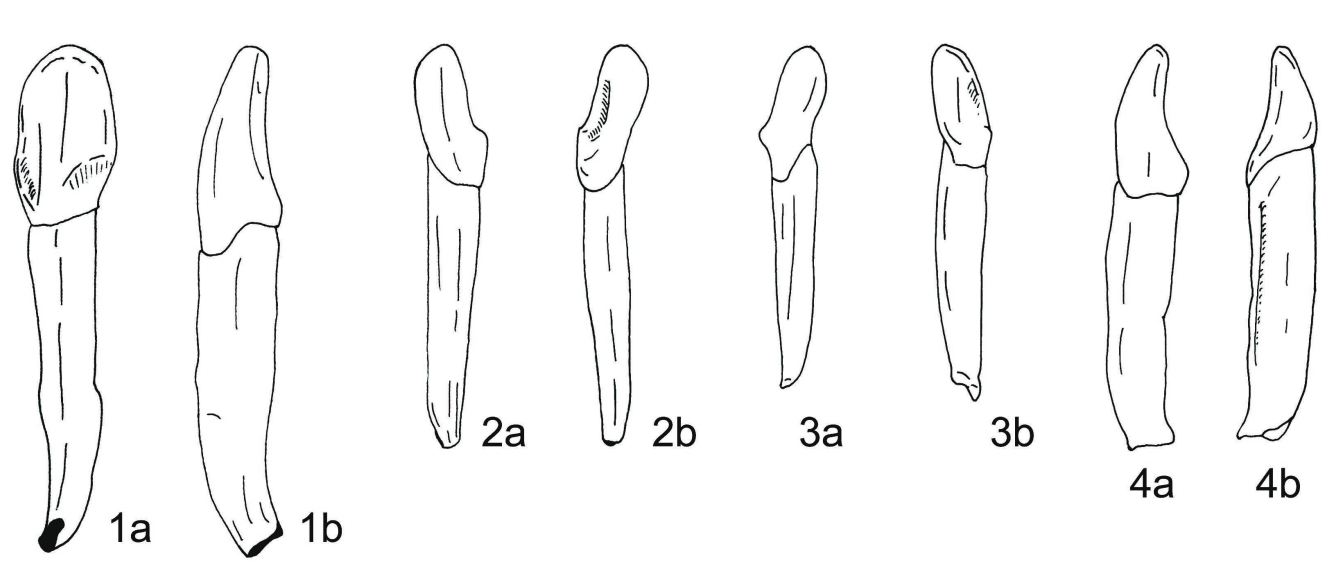

reversed

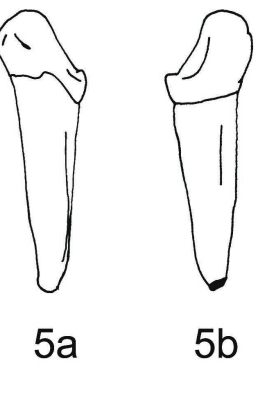

reversed
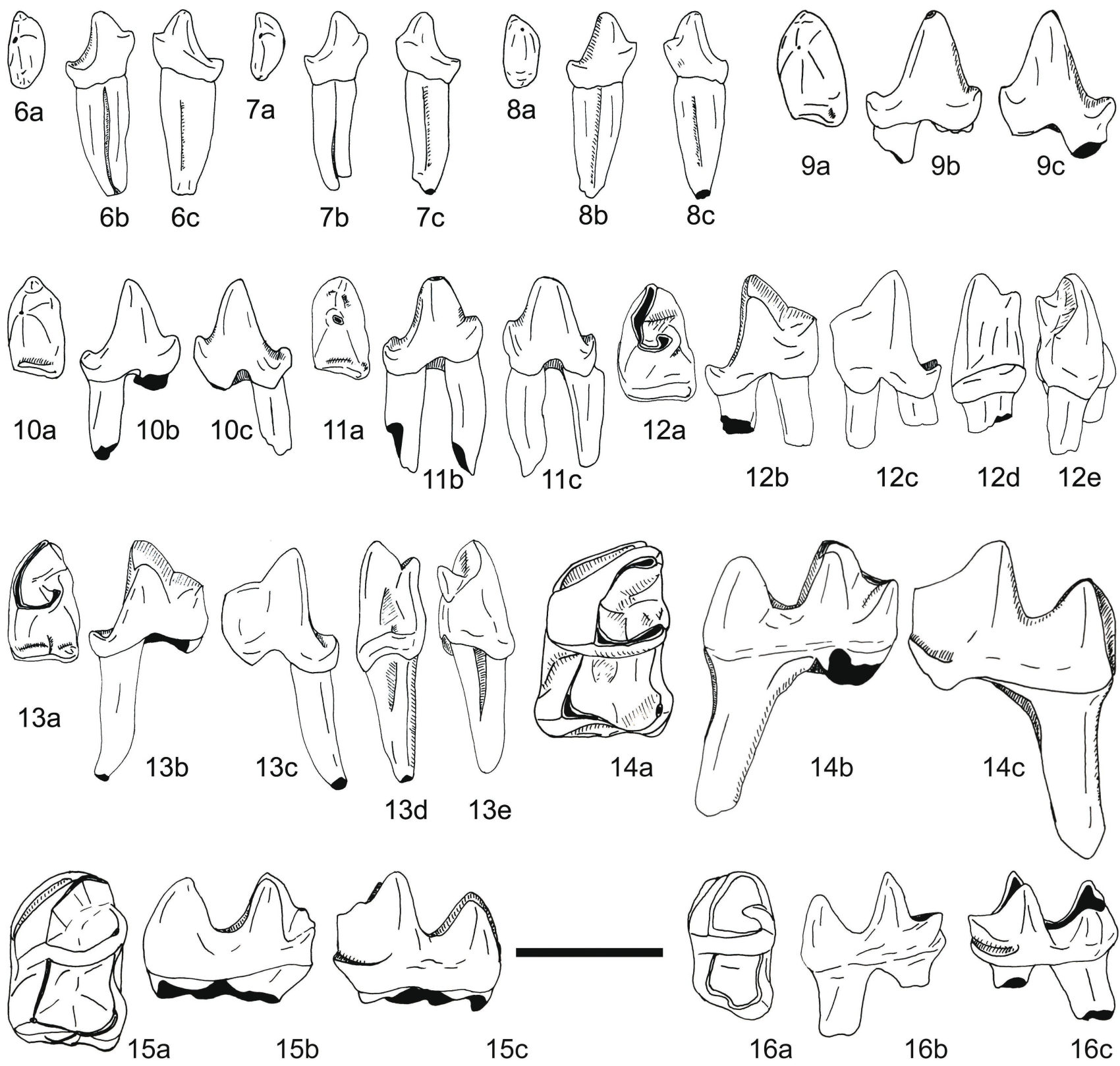